\title{
Strength Analysis and Optimization Design of A Platform Used for Transporting and Releasing Large Stratospheric Airship
}

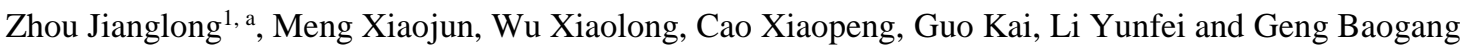 \\ ${ }^{1}$ Northwest Institute of Nuclear Technology, Xi'an, 710024, China.
}

\begin{abstract}
It is important to transport and release a large airship safely because of the big size. In order to complete the transfer of large stratospheric airship, a truss transfer platform is built. Based on MATLAB and FEMAP, a semi-parametric method is used to establish the model of the platform which is consisted of rectangular steel tube in this paper. With a finite element software ABAQUS, a study of mechanical property of the platform is carried out. The simulation result shows that the force of the platform is mainly caused by the weight of trusses. The force of airship and other attached devices has little effect on the structure. Then, optimal parameters of extended platform are obtained according to the mechanical properties and optimization design. At last, the simulation results are verified by the experiment.
\end{abstract}

\section{Introduction}

With the development of airship technology, many countries focus on stratospheric airship because of its advantages in spying, communications relay, earth observation and so on $[1,2]$. Stratospheric airships are generally in the tens of thousands to hundreds of thousands of cubic meters which makes it difficult to transfer and release. It is significantly influenced by the surface wind because of a high volume. Thus, the stratospheric airship has a higher requirement in the transport process. In order to complete the airship transfer mission, a truss platform with the size of $85 \mathrm{~m} \times 51 \mathrm{~m} \times 1.6 \mathrm{~m}$ is built.

The main structure of the platform is truss that consist of rectangular steel tube. Ge W analysis $120 \mathrm{~m}$ large span truss-string structure with finite element software of SAP2000 and MIDAS[3], and some other authors also use finite element software to model and analyse[5,6,8-10]. For a large structure, the disadvantage of using finite element software to model directly is wasting time.

In this paper, we design a new modeling method, a semi-parametric method, which based on MATLAB and FEMAP to establish the model of the platform. ABAQUS is used to simulate. Matlab uses the programing method to construct truss structure model and FEMAP is used to model other complex structure of the platform. When the structural optimization is carried out, this method can significantly improve the modeling efficiency. This paper has completed the mechanical analysis of existing structure Based on the simulation results, a new construction scheme is presented for the extended platform. In the end, the simulation results are verified by the experiment.

\section{The semi-parametric modeling method based on MATLAB and FEMAP}

The main structures of the platform are shown in the figure 1. The truss structure, shown in figure 2(a), is welded by angle iron and rectangular steel tube of different sizes. Considering the main load of the rectangular steel tube is bending moment, the model is complete with beam element. The shell element is used to simulate angle iron, hexagonal connectome and cross truss of driver.

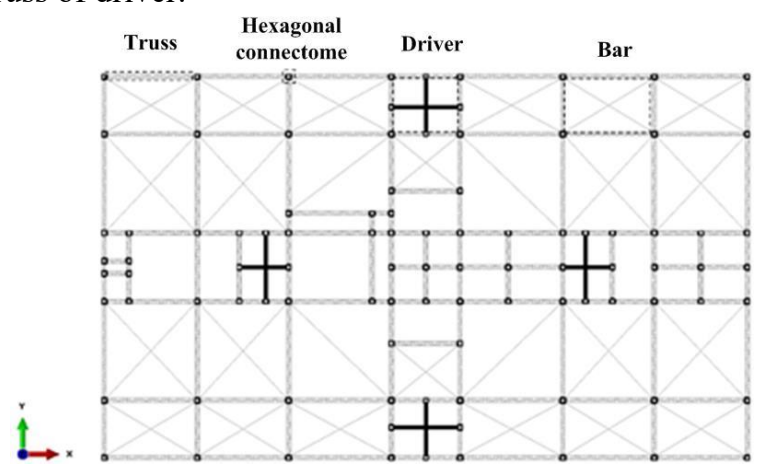

Figure 1. The main structures of the platform

There are 149 trusses of the same structure in the platform, so a parametric method based on MATLAB is used to complete the truss model. Compared with the method based on the finite element software, the nodes and elements information obtained by the parametric modelling method can be used to simulate directly. Besides, it can conveniently modify parameters of truss, which will significantly improve the efficiency of the optimization. 


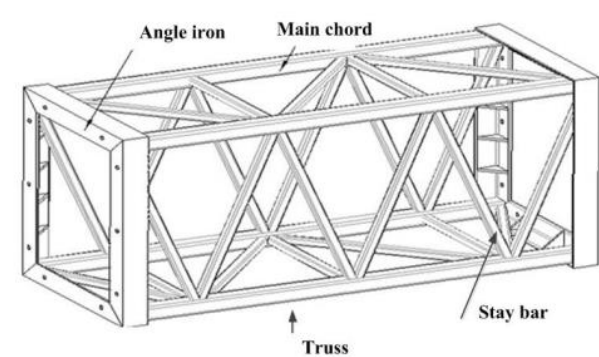

(a)

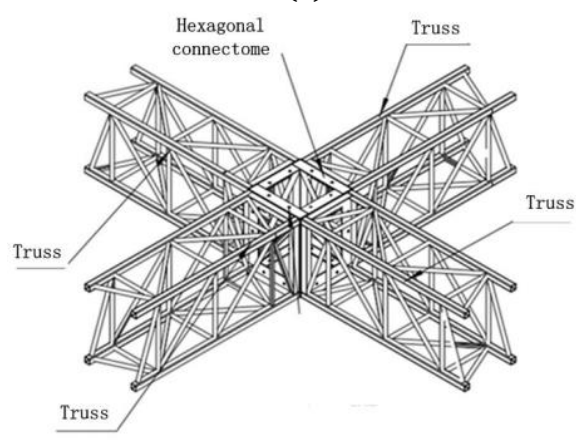

(b)

Figure 2. The truss structure (a) and link mode of truss (b)

The finite element method based on FEMAP is adopted for modelling the rest of the platform, for example the hexagonal connectome and the cross truss. There are 96 hexagonal connectomes of same size with different location in the platform. In order to model these structures efficiently, one of the hexagonal connectomes is modelled firstly and then copy it to corresponding location by MATLAB. The same method is used to establish the model of 4 cross trusses.

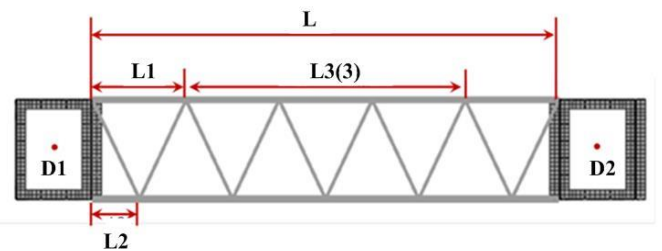

(a)

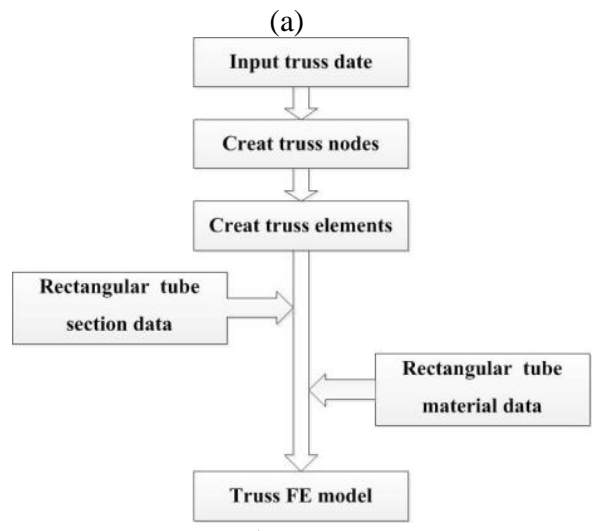

(b)

Figure 3. Modeling required parameters (a) and modeling process of truss (b)

\section{Simulation of the finite element model and structure optimization of the truss}

\subsection{Working condition and boundary condition}

There are 6 winding engines, 2 working planes and 1 mooring tower fixed to the corresponding position that shown in figure 4(a) on the platform. Each winch is pulled by the airship along the $\mathrm{z}$ axis. The weight of the platform, winding engines, working planes, mooring tower along the $-\mathrm{Z}$ axis and the force of airship along the $\mathrm{z}$ axis are the loads of the platform. The boundary condition of the platform is the supporting of wheel that along the $\mathrm{z}$ axis. The position of wheels shown in figure 4(b).

Finally, the finite element model of the whole platform is obtained, which has 215969 nodes, 25218 beam elements and 179552 shell elements.

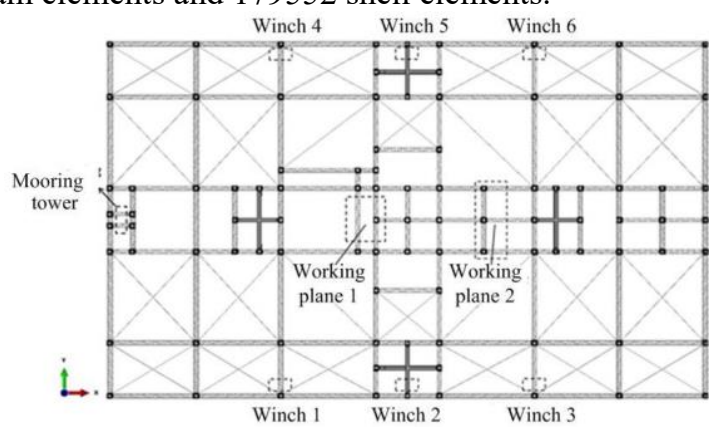

(a)

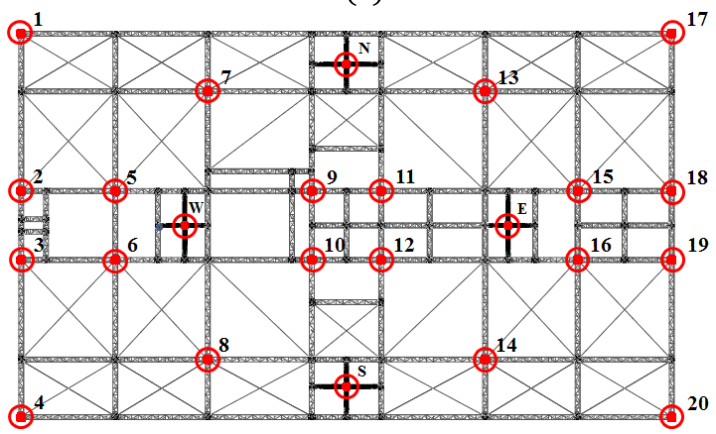

(b)

Figure 4. The position of the load(a) and wheels (b)

Table 1. The force on the platform

\begin{tabular}{|c|c|c|c|c|}
\hline Force & $\begin{array}{c}\text { The weight } \\
\text { of the truss }\end{array}$ & $\begin{array}{c}\text { The } \\
\text { weight } \\
\text { of the } \\
\text { mooring } \\
\text { tower } \\
\text { weight } \\
\text { of } \\
\text { winch } \\
\text { and } \\
\text { working } \\
\text { plane }\end{array}$ & $\begin{array}{c}\text { The } \\
\text { pull of } \\
\text { airship }\end{array}$ \\
\hline Value & $\begin{array}{c}\mathrm{g}=9.8 \mathrm{~N} / \mathrm{kg} \\
\rho=7850 \mathrm{~kg} / \mathrm{m}^{3}\end{array}$ & $42140 \mathrm{~N}$ & $9800 \mathrm{~N}$ & $9800 \mathrm{~N}$ \\
\hline
\end{tabular}

\subsection{Simulation Results and optimized results}

The finite element software ABAQUS is used to complete the simulation. Stress nephogram of the trusses is shown in figure 5. The maximum force is $71.73 \mathrm{MPa}$, which is far below the allowable stress of Q235 steel. In 
order to analyse the influence of external forces on the platform structure, the weight of the platform is not considered. The stress of the platform under external forces is analysed. The result shows that the maximum stress of the trusses is $26.8 \mathrm{MPa}$. According to the simulation, conclusions can be obtained that the weight of the trusses is the main load of the platform, the structural strength of the trusses is in surplus.

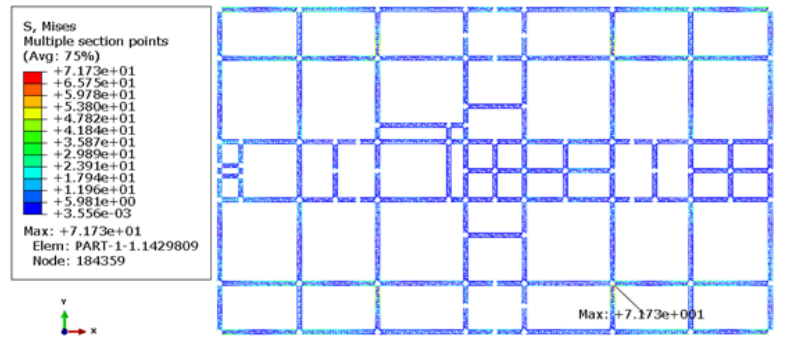

Figure 5. Stress nephogram of the trusses

The platform needs to be extended to 120 meters. In order to lighten platform weight, the expanded areas will use smaller cross section size steel pipe. Firstly, model of the extended platform established with original steel tube, then the cross section size of expanded areas will be optimized. Simulation of various situations of expanded platform is carried out. Figure 7 shows the stress-size of the extended platform. According to the chart, 30_3/14_1.5 is an optional solution. It means cross section size of the main chord is 30_3 (30 instead of the cross section length and 3 instead of the thickness of the tube) and size of stay bar is 14_1.5.

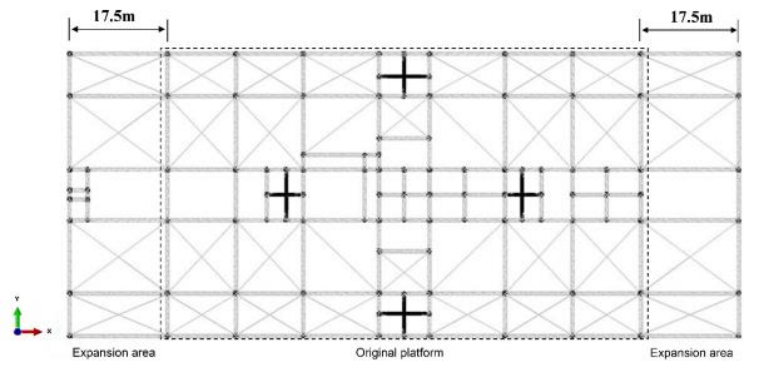

Figure 6. The extended platform

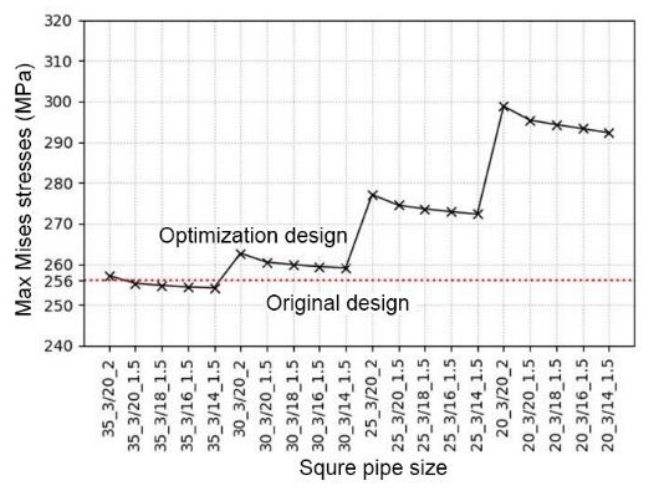

Figure 7. The stress of truss

\section{Experimental verification}

To verify the accuracy of the simulation, the experiment measured the support of some wheels. The simulation data and experimental data are compared as shown in table 2. The minimum inaccuracy is $-1.89 \%$ and the maximum inaccuracy is $-20.44 \%$. Because some equipment, such as battery cupboards which are located in the center of the platform, are not taken into account, the simulation data is less than the experimental data. The force inaccuracy of the wheels near the center of the platform $(7,8,13,14)$ is bigger. The inaccuracy of wheels far from the center of the platform $(1,4,17,20)$ is within the allowable range. Thus, the simulation data is believed to be reliable in this paper.

Table 2. Comparison of experimental data and simulation data

\begin{tabular}{|c|c|c|c|}
\hline \multirow{2}{*}{ wheel } & \multicolumn{2}{|c|}{ Wheel reaction(kg) } & \multirow{2}{*}{ inaccuracy } \\
\cline { 2 - 3 } & $\begin{array}{c}\text { Experimental } \\
\text { data }\end{array}$ & $\begin{array}{c}\text { Simulation } \\
\text { data }\end{array}$ & \\
\hline 1 & 2844 & 2641 & $-7.13 \%$ \\
\hline 4 & 2592 & 2645 & $2.03 \%$ \\
\hline 17 & 2687 & 2636 & $-1.89 \%$ \\
\hline 20 & 2680 & 2645 & $-1.31 \%$ \\
\hline 7 & 5220 & 4626 & $-11.38 \%$ \\
\hline 8 & 5798 & 4655 & $-19.71 \%$ \\
\hline 13 & 5850 & 4840 & $-17.27 \%$ \\
\hline 14 & 5850 & 4654 & $-20.44 \%$ \\
\hline
\end{tabular}

\section{5 conclusion}

Based on MATLAB and FEMAP, finite element model of the platform is established by the semi-parametric method. This method is an effective way to establish a complex model.

The mechanical properties of the platform are analyzed based on the finite element software. Simulation results show that the weight of trusses is the main load of the platform and the structural strength of the trusses is in surplus. According to the simulation results, the optimized design of square section size is carried out. The results indicate that the size 30_3/14_1.5 of the square tube is the optional solution. At last, the simulation data is verified by an experiment.

\section{References}

1. Wang M, Huang X. Development of Stratospheric Airship Platform and Its Key Technology Analysis. Automatic Measurement and Control, 26(8):5890(2007)

2. Zhao D, Liu D, Sun K, et al. Research status, technical difficulties and development trend of stratospheric airship. Acta Aeronautica Et Astronautica Sinica, 37(1):45-56(2016)

3. Ge W, Li Z, Shu G. Analysis and Design of $120 \mathrm{~m}$ Large Span Truss-String Structure. Jiangsu Construction, (2): 30-33(2017) 
4. Liang J, Huang Z. Design and Analysis of A Sunshine Greenhouse Steel Tube Truss-Arch Structure. Journal of Guizhou University (Natural Sciences), 32(5): 121-125(2015)

5. Sai F, Nai J. Analysis and design of steel truss structure in a roof. Technological Innovation and Application, (5): 241(2007)

6. Li L, Wang Y, Wang D, et al. Structural analysis and design of a large span tube truss. In: Tianjing, China, (2017)

7. Wang B, Chen W. Analysis of the threedimensional truss structure of a gymnasium roof. In: Tianjing, China, (2014)

8. Zhao J, Zhang J, Wu Z. Analysis and design of large-span transfer truss structure. Building Structure, 46(11): 21-26(2016)

9. Mihal Victor, Marian Bunea, et al. Truss systems and shape optimization. AIP Conference Proceedings 1863, 420004(2017).

10. Eric C.Clough, Jie Ensberg, et al. Mechanical performance of hollow tetrahedral truss cores. International Journal of Solids and Structures, 91:115-126(2016) 